\title{
○ẹmestáo
}

\section{O contributo da gestão de documentos na gestão do conhecimento nas organizações: uma abordagem exploratória}

\author{
Thiago de Oliveira Vieira \\ Doutorando; Universidade de Coimbra, Coimbra, Portugal; \\ thiagoov@globo.com
}

\begin{abstract}
Resumo: Esta pesquisa verifica como a gestão de documentos pode contribuir com a gestão do conhecimento nas organizações, explorando as suas aproximações e os seus distanciamentos. Trata-se de uma abordagem exploratória, cujo percurso metodológico parte de uma revisão de literatura para posterior análise comparada entre os dois modelos de gestão que são objeto deste trabalho. Os resultados apontam mais para uma aproximação do que para um distanciamento, evidenciando os diversos contributos da gestão de documentos no processo de gestão do conhecimento nas organizações. Concluise que a gestão do conhecimento pode beneficiar-se de um ativo de conhecimento orgânico de qualidade, no que tange aos documentos arquivísticos, quando resultado da aplicação da gestão de documentos. Isto é, um ativo orgânico organizado, acessível, contextualizado em sua função/atividade e estrutura organizacional e com seus valores identificados e prazos de guarda estabelecidos.
\end{abstract}

Palavras-chave: Gestão do Conhecimento. Gestão de Documentos. Ativos de Conhecimento. Documento Arquivístico.

\section{Introdução}

O conhecimento tem despertado o foco das organizações como elemento central dentro de um processo de busca de mais vantagem competitiva (MOLEIRO MARTINS, 2010; OWEN, 1999; WIIG, 1997). A gestão do conhecimento auxilia as instituições na inovação de processos, produtos e serviços; além disso, contribui para evitar a perda e a obsolescência do conhecimento.

Tendo como perspectiva que a informação é uma das bases para o conhecimento (MOLEIRO MARTINS, 2010), as informações produzidas no decorrer das funções/atividades das organizações constituem uma das dimensões da gestão do conhecimento, devendo, para isso, estarem organizadas e acessíveis. Essas informações são essenciais no processo de tomada de decisões 
e prestação de contas; logo, a rapidez no acesso e uso das informações são vitais para as instituições na garantia da vantagem competitiva.

Uma informação registrada em um suporte constitui um documento (CAMARGO; BELLOTTO, 1996). Os documentos produzidos em razão de uma função/atividade de uma instituição (pública ou privada) ou pessoa dotada de organicidade - registradas nos mais diversos tipos de suportes/formatos, analógicos ou digitais - são consideradas documentos arquivísticos.

Importa delimitar neste estudo que o arquivo, enquanto conjunto de documentos arquivísticos, constitui o estoque informacional de uma organização e, em um processo de assimilação e modificação da estrutura de conhecimento dos seus funcionários, gera conhecimento para a própria organização. Nesse contexto, o arquivo é uma fonte informacional passível de gerar conhecimento para a instituição que o produz, desde que esteja organizado e acessível.

A gestão de documentos, surgida após a Segunda Guerra Mundial, tem por objetivo garantir a economia e a eficácia administrativa a partir da intervenção nas fases de produção, uso e destinação final dos documentos de arquivo (JARDIM, 1987).

A partir do exposto, colocam-se as seguintes questões de pesquisa: quais as aproximações e os distanciamentos entre a gestão de documentos e a gestão do conhecimento? Como aspectos inerentes à gestão de documentos podem colaborar para uma melhor gestão do conhecimento?

Parte-se do pressuposto que a gestão de documentos contribui com a gestão do conhecimento em duas dimensões: a organização física e intelectual dos documentos e a seleção dos documentos para eliminação ou guarda permanente durante todo o seu ciclo vital, conferindo economia, eficiência e eficácia administrativa às organizações.

Nesta pesquisa, utiliza-se o conceito de organização da informação, que segundo Brascher e Café (2008):

Em nossa visão, temos dois tipos distintos de processos de organização, um que se aplica às ocorrências individuais de objetos informacionais - o processo de organização da informação, e outro que se aplica a unidades do pensamento (conceitos) - o processo de organização do conhecimento. (BRASCHER; CAFÉ, 2008, p. 6). 
Ao analisar os contributos da gestão de documentos dentro de um processo de gestão do conhecimento, refere-se ao conceito de organização da informação, mas especificamente no que concerne às atividades da gestão de documentos.

Os objetivos da pesquisa são entender o papel da gestão de documentos na gestão do conhecimento, a partir da compreensão do documento arquivístico como um ativo dentro de um processo de gestão do conhecimento, e estabelecer as aproximações e os distanciamentos desses dois processos de gestão a partir de uma comparação de suas origens, objetos e objetivos.

Uma pesquisa avançada foi realizada nos Repositórios Científicos de Acesso Aberto de Portugal (RCAAP) ${ }^{1}$, que agrega as publicações científicas depositadas no Portal Brasileiro de Publicações Científicas em Acesso Aberto (OASISbr), no dia 30 de novembro de 2017, com a combinação de termos gestão de documentos e gestão do conhecimento, por meio dos seguintes filtros de pesquisa: i) procura dos termos no campo descrição; ii) sem limitação de ano; iii) incluindo busca em recursos portugueses e brasileiros.

Foram localizadas apenas seis produções acadêmicas que relacionassem esses dois conceitos (um artigo, duas monografias de graduação ou licenciatura e três dissertações de mestrado). Em uma breve análise dos resumos apresentados, verificou-se que apenas quatro (três dissertações de mestrado e uma monografia de graduação ou licenciatura) desses documentos estabeleciam alguma relação entre ambos os termos (gestão de documentos e gestão do conhecimento).

Uma atualização da pesquisa realizada no RCAAP, com os mesmos critérios descritos anteriormente, foi realizada no dia 1 de abril de 2019, obtendo como resultado sete produções acadêmicas (quatro dissertações de mestrado, dois artigos científicos e um pôster apresentado em evento científico). A partir de uma análise destes materiais, verificou-se que duas dissertações de mestrado, dois artigos científicos e um pôster apresentado em evento científico apresentavam uma relação entre ambos os conceitos estudados neste trabalho.

Além do RCAAP, realizou-se outra consulta na Base de Dados em Ciência da Informação (BRAPCI) no dia 1 de abril de 2019, utilizando a 
combinação dos termos gestão de documentos e gestão do conhecimento em todos os campos e sem restrição de data. Como resultado, foram obtidos três artigos científicos, sendo que dois já haviam sido localizados na última pesquisa realizada no RCAAP.

O desenvolvimento deste estudo justifica-se, portanto, pela pouca produção teórica encontrada na área, ao menos em língua portuguesa e com os critérios de pesquisa bibliográfica apresentados, relacionando a gestão de documentos com a gestão do conhecimento, mais especificamente as contribuições da gestão de documentos nos ativos organizacionais, em particular o ativo de conhecimento orgânico (NONAKA; TOYAMA; KONNO, 2000), no qual os documentos arquivísticos inserem-se como fonte de registro, transferência e produção de conhecimento.

A sua relevância reside na tentativa do estabelecimento das interconexões entre as fases da gestão de documentos e da gestão do conhecimento, explicitando os pontos em que um modelo de gestão - de documentos - pode contribuir com o outro modelo de gestão - de conhecimento. Essa proposta está assentada em um enquadramento que será exposto na próxima seção, dedicada ao contexto metodológico deste artigo científico.

\section{Metodologia}

Em termos metodológicos, para alcançar os objetivos propostos, esta pesquisa foi executada em duas etapas.

Foi realizada uma revisão de literatura, de caráter não exaustivo, acerca dos temas centrais propostos nesta investigação: gestão de documentos e gestão do conhecimento.

Para executar a revisão de literatura, efetuou-se uma pesquisa bibliográfica não estruturada e intencional, realizada na Web of Science e no Google Scholar, entre os meses de outubro e novembro de 2017, utilizando os termos gestão de documentos e gestão do conhecimento. Oportuno destacar que a intencionalidade na escolha das referências relativas à gestão de documentos deve-se a uma maior familiaridade do autor com essa temática. Com relação à gestão do conhecimento, a seleção foi predominantemente feita a 
partir das bases de dados mencionadas acima, utilizando como critério de distinção as referências com alto grau de impacto de citações (citado por), utilizando a quantificação disponibilizada nessas ferramentas.

Elaborou-se uma lista com a bibliografia escolhida, que foi submetida à validação de um(a) especialista (doutor(a) e professor(a) universitário(a) que possui atuação e pesquisas nas duas áreas objeto deste trabalho: gestão de documentos e gestão do conhecimento), conferindo maior grau de consistência aos autores e referências selecionadas, reduzindo assim o grau de intencionalidade e aumentando a pertinência das fontes bibliográficas.

Buscou-se, na revisão de literatura, a utilização de referências clássicas e contemporâneas, permitindo uma visão mais ampla dos dois conceitos que seriam alvo da revisão. O Quadro 1 contextualiza as referências utilizadas na revisão de literatura.

Quadro 1 - Referências para enquadramento da revisão de literatura

\begin{tabular}{|c|c|}
\hline Gestão & Referências \\
\hline \multirow{3}{*}{ Documento } & RHOADS, 1983; JARDIM, 1987; COUTURE; \\
& ROUSSEAU, 1998; LLANSÓ SANJUAN, 2006; \\
& INDOLFO, 2007; SILVA et al., 2009; JARDIM, \\
& 2015. \\
\hline \multirow{3}{*}{ Conhecimento } & SHARIQ, 1997; WIIG, 1997; NONAKA; KONNO; \\
& VALENTIM, 2008; MOLEIRO MARTINS, 2010; \\
& TZORTZAKI; MIHIOTIS, 2014. \\
\hline
\end{tabular}

Fonte: Elaborado pelo autor.

Ressalta-se que, no âmbito da gestão do conhecimento, a bibliografia sustenta-se predominantemente em referências internacionais; na esfera da gestão de documentos, utilizou-se autores nacionais e internacionais (Brasil, Canadá, Espanha, Estados Unidos e Portugal), apesar de terem sido selecionados textos traduzidos em língua portuguesa ou espanhola.

Importa destacar que algumas referências foram utilizadas para explicar os conceitos de documento, documento arquivístico, informação e conhecimento, permitindo enquadrar conceitualmente os dois modelos de gestão a partir de perspectivas mais sólidas de entendimento.

Para além de uma abordagem teórica sobre a gestão de documentos e a gestão do conhecimento, a revisão de literatura foi concebida como um recurso 
metodológico para a fase posterior, de análise comparada entre os dois modelos de gestão. Para isso, a revisão de literatura (seção 3) foi estruturada de acordo com os seguintes eixos: origens, objetos, objetivos e metodologia.

A segunda etapa consistiu em uma breve análise comparada (seção 4) entre os dois modelos de gestão propostos na pesquisa realizada integralmente a partir dos eixos apresentados na revisão de literatura, buscando as aproximações e os distanciamentos entre eles, além da identificação dos contributos da gestão de documentos na gestão do conhecimento nas organizações.

\section{Revisão de Literatura: documento, documento arquivístico, informação e conhecimento}

O ponto de partida para compreender as origens, objetos e objetivos da gestão do conhecimento e da gestão de documentos é uma breve elucidação dos conceitos de documento, documento arquivístico, informação e conhecimento. Sabe-se que há uma diversidade de conceituações para esses termos, mas esta pesquisa ocupa-se apenas em estabelecer, brevemente, as suas diferenciações.

Em um sentido mais amplo, um documento é informação registrada em um suporte (CAMARGO; BELLOTTO, 1996). Trata-se, portanto, de uma unidade de registro de informações, independente do suporte onde estão registradas as informações (ARQUIVO NACIONAL, 2005). A ideia de um suporte material para registro da informação é central no conceito de documento.

Partindo do documento para o documento arquivístico, este “[...] só tem sentido se relacionado ao meio que o produziu. Seu conjunto tem de retratar a infraestrutura e as funções do órgão gerador." (BELLOTTO, 2004, p. 28). Um documento arquivístico é aquele "[...] produzido e acumulado por uma entidade coletiva, pública ou privada, pessoa ou família, no desempenho de suas atividades, independentemente da natureza do suporte." (ARQUIVO NACIONAL, 2005, p. 27) e dotado de organicidade - característica singular que difere os documentos arquivísticos de outros documentos (BELLOTTO, 2004).

Para Cruz Mundet (2012), o documento de arquivo é uma: 


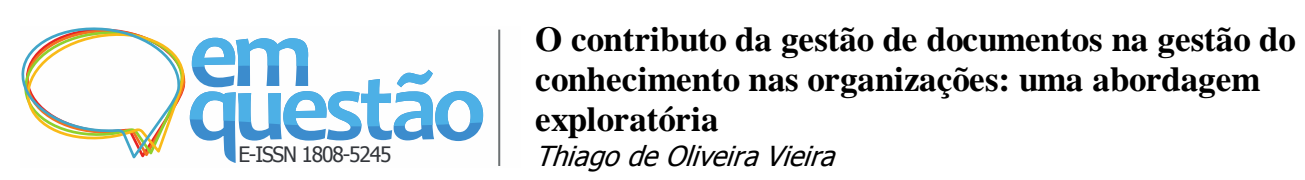

[...] entidade de informação de caráter único, produzida ou recebida na iniciação, desenvolvimento ou finalização de uma atividade; cujo conteúdo estruturado e contextualizado se apresenta como evidência e suporte das ações, decisões e funções próprias das organizações e das pessoas físicas e jurídicas. Os componentes de um documento são conteúdo (a mensagem), estrutura (o uso de cabeçalhos e outros dispositivos para identificar e etiquetar partes do documento), contexto (o entorno e a rede de relações nas quais o documento tenha sido criado e utilizado) e apresentação (consiste na combinação do conteúdo, da estrutura e, no caso dos documentos eletrônicos, também do software de apresentação utilizado). (CRUZ MUNDET, 2012, p. 57, tradução nossa).

Portanto, para além da ideia de documento (enquanto informação agregada em um suporte), o documento arquivístico é produzido para efetivar alguma ação, no âmbito das funções e atividades de uma instituição, e interrelacionado com os demais documentos produzidos para esta mesma ação (ideia do conjunto orgânico de documentos).

Já no tocante à informação, para Le Coadic (2004), é:

[...] um conhecimento inscrito (registrado) em forma escrita (impressa ou digital), oral ou audiovisual, em um suporte. A informação comporta um elemento de sentido. É um significado transmitido a um ser consciente por meio de uma mensagem inscrita em um suporte espacial-temporal: impresso, sinal elétrico, onda sonora, etc. Inscrição feita graças a um sistema de signos (a linguagem), signo este que é um elemento da linguagem que associa um significante a um significado: signo alfabético, palavra, sinal de pontuação. (LE COADIC, 2004, p. 4).

Pinheiro (2004) chama a atenção para essa materialização que tradicionalmente ocorre ao se definir informação. A informação de que trata a Ciência da Informação também pode estar em um diálogo, em uma comunicação informal, nas bases de dados, em uma inovação ou na internet. A autora propõe um alargamento das fronteiras da informação, não só a materializada, mas também as informações enquanto um fluxo de mensagens.

A informação transforma-se em conhecimento na medida em que é capaz, por meio de sua utilização, de alterar um estado de conhecimento de um indivíduo. O conhecimento é resultado do uso producente da informação (MOLEIRO MARTINS, 2010).

Por fim, em relação ao conhecimento, Nonaka, Toyama e Konno (2000) distinguem duas dimensões epistemológicas: conhecimento tácito (pessoal) e conhecimento explícito (codificado). O conhecimento explícito é aquele em que 
se pode registrar, enquanto o conhecimento tácito é o conhecimento da observação e da experiência, que não se consegue registrar por meio da linguagem. $\mathrm{O}$ conhecimento explícito transforma-se em informação codificada para uma possível utilização e transformação em novo conhecimento.

Diante do exposto, pode-se afirmar que a informação, materializada e orgânica, faz-se necessária para a existência de um documento arquivístico. No que concerne ao conhecimento, a informação é uma ferramenta ou meio para produção e registro do conhecimento (MOLEIRO MARTINS, 2010), ou seja, "[...] um fluxo de mensagens ou significados que pode adicionar ou alterar o conhecimento." (MOLEIRO MARTINS, 2010, p. 16).

\subsection{Gestão do conhecimento}

Ao longo das décadas de 1980 e 1990 é possível perceber o surgimento de uma diversidade de procedimentos que visam a melhoria das atividades nas organizações: reengenharia de processos de negócios, sistemas de gerenciamento da informação, benchmarking, entre outros processos para o aprimoramento das empresas (TZORTZAKI; MIHIOTIS, 2014). Estas novas metodologias de negócios foram fruto de uma economia cada vez mais industrializada e competitiva (WIIG, 1997).

É nesse cenário que o conhecimento se torna o principal ativo dentro de uma organização empresarial. Para Shariq (1997), a gestão do conhecimento, enquanto disciplina, constituía um desafio. Para o autor, esta matéria de gestão do conhecimento deveria "[...] responder com sucesso à diversas necessidades de organizações baseadas no conhecimento e nos profissionais do conhecimento [...]" (SHARIQ, 1997, p. 76, tradução nossa).

No que tange aos seus objetivos, a gestão do conhecimento visa identificar e analisar o conhecimento presente nas organizações, com o propósito de desenvolver procedimentos e sistemas para a geração, armazenamento, distribuição e uso do conhecimento na própria organização (OWEN, 1999). O autor ainda destaca que a gestão do conhecimento objetiva a criação de valor agregado para a organização em três níveis distintos: "Melhorias dos processos de negócios existentes [...] [,] Desenvolvimento de 
novos produtos e serviços [...] [e] melhorar a posição estratégica [...]" (OWEN, 1999, p. 8, tradução nossa).

A gestão do conhecimento em uma organização faz a empresa funcionar de forma inteligente, garantindo sua viabilidade e sucesso, além de realizar o melhor valor dos seus ativos de conhecimento (WIIG, 1997). Ainda segundo o autor, para atingir estes objetivos, a empresa precisa "[...] criar, transformar, organizar, implementar e utilizar os seus ativos de conhecimento de forma eficaz." (WIIG, 1997, p. 8, tradução nossa).

Uma organização dispõe de recursos que constituem seus ativos de conhecimento. Nonaka e Konno (1998) e Nonaka, Toyama e Konno (2000) classificam estes recursos em quatro categorias:

a) Ativos de conhecimento empírico (conhecimento tácito compartilhado por meio de experiências comuns);

b) Ativos de conhecimento conceitual (conhecimento explícito articulado por meio de imagens, símbolos e linguagem);

c) Ativos de conhecimento regular (conhecimento tácito rotineiro e baseado nas ações e práticas da organização);

d) Ativos de conhecimento orgânico (conhecimento explícito agrupado e sistematizado).

O Quadro 2 sintetiza os ativos de conhecimento:

Quadro 2 - Ativos de conhecimento

\begin{tabular}{|l|l|}
\hline \multicolumn{1}{|c|}{$\begin{array}{c}\text { Ativo de conhecimento } \\
\text { empírico }\end{array}$} & \multicolumn{1}{|c|}{$\begin{array}{c}\text { Ativo de conhecimento } \\
\text { conceitual }\end{array}$} \\
\hline $\begin{array}{l}\text { - Aptidões e know-how dos } \\
\text { indivíduos; } \\
\text { - Atenção, afeição, confiança e } \\
\text { segurança; }\end{array}$ & $\begin{array}{l}\text { - Conceitos de produto; } \\
\text { - Design; } \\
\text { - Energia, emoção e tensão. }\end{array}$ \\
\hline $\begin{array}{l}\text { Ativo de conhecimento } \\
\text { regular }\end{array}$ & $\begin{array}{l}\text { Ativo de conhecimento } \\
\text { orgânico }\end{array}$ \\
\hline - Know-how nas operações & - Documentos, especificações e \\
diárias; & manuais; \\
- Rotinas organizacionais; & - Bases de dados; \\
- Cultura organizacional. & - Patentes e licenças. \\
\hline
\end{tabular}

Fonte: Elaborado pelo autor. 
Importante ressaltar que o conhecimento tácito está nos fluxos e nas interações entre as pessoas, enquanto o conhecimento explícito está materializado e disponível para assimilação e produção de novo conhecimento. Os ativos de conhecimento constituem-se em recursos específicos (inputs e outputs) de uma organização, ou seja, a sua base de conhecimento (MOLEIRO MARTINS, 2010).

As diversas possibilidades de interações entre o conhecimento tácito e explícito são identificadas em uma matriz, amplamente conhecida, designada modelo ou processo Socialização, Exteriorização, Combinação e Internalização (SECI) de conversão de conhecimento, processo este que funciona em um movimento espiral (NONAKA; TOYAMA; KONNO, 2000), conforme demonstrado na Figura 1.

Figura 1 - Processo SECI de conversão do conhecimento

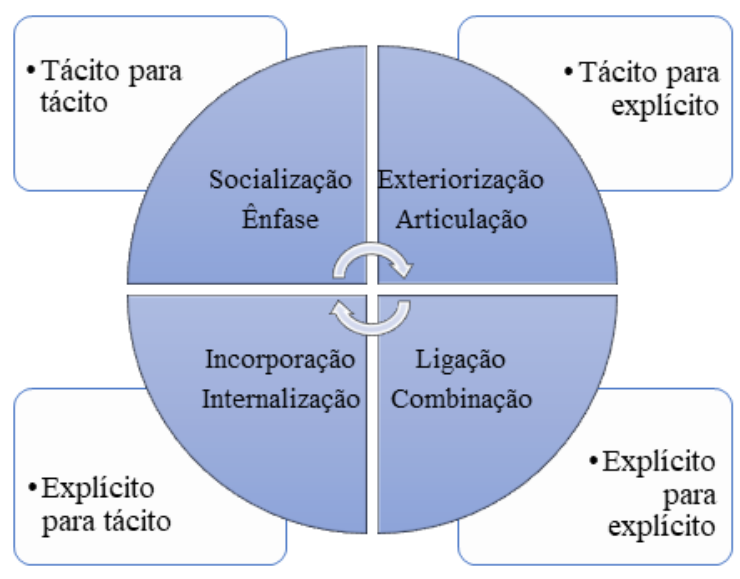

Fonte: Nonaka e Konno (1998) e Nonaka, Toyama e Konno (2000).

Através do processo de conversão, os conhecimentos tácito e explícito expandem em qualidade e quantidade. Existem quatro modos de conversão do conhecimento. São eles: (1) a socialização (a partir do conhecimento tácito em conhecimento tácito); (2) externalização (a partir do conhecimento tácito em conhecimento explícito); (3) combinação (a partir do conhecimento explícito para o conhecimento explícito); e (4) internalização (conversão do conhecimento explícito em conhecimento tácito) (NONAKA; KONNO, 1998; NONAKA; TOYAMA; KONNO, 2000). 
Para Owen (1999), o conhecimento tácito e o conhecimento explícito podem ser diferenciados da seguinte maneira: “[...] diferença entre o que eu sei como um indivíduo e o que nós sabemos como um grupo de indivíduos que trabalham juntos." (OWEN, 1999, p. 10, tradução nossa). O autor ainda distingue duas formas de conhecimento, o conhecimento como conceito e o conhecimento como objeto (OWEN, 1999). Enquanto conceito, o conhecimento serve como ponto de partida para pensar sobre as organizações, enquanto objeto refere-se ao conhecimento que pode ser representado, armazenado e transferido (conhecimento explícito). Nesse sentido, para Owen (1999), uma das principais questões para o conhecimento como conceito é o processo de externalização, ou seja, a transformação do conhecimento tácito em conhecimento explícito. Já na perspectiva do conhecimento como objeto, o ponto central está na produção, aquisição, organização, armazenamento e difusão do conhecimento nas organizações (OWEN, 1999).

Nessa perspectiva, pode-se considerar que a gestão do conhecimento se caracteriza pela implantação de um ambiente organizacional favorável à produção, aquisição, compartilhamento e uso de conhecimento (VALENTIM, 2008), com enfoque no conhecimento como um conceito e no conhecimento tácito dos indivíduos ou no coletivo da organização (OWEN, 1999). Além disso, mapeia os fluxos informais existentes nos ambientes organizacionais, com o objetivo de materializar o conhecimento tácito em conhecimento explícito (NONAKA; TOYAMA; KONNO, 2000), possibilitando novos usos pela organização.

A gestão do conhecimento atua essencialmente nos fluxos informais de informação e no conhecimento tácito, resgatando informações internas fragmentadas e transformando-as em representações estruturadas e significativas (conhecimento explícito) capazes de auxiliar o processo de inteligência competitiva, assim como corrigir ações em situações críticas, identificar oportunidades e gerar atividades antecipativas frente à concorrência. (VALENTIM et al., 2003, p. 9)

A partir da construção teórica acima, é possível perceber a importância do conhecimento nas organizações, o seu papel como um ativo e como um elemento central em um processo de inovação. Nesse sentido, a gestão do 
conhecimento possui uma função estratégica nas instituições, gerindo o conhecimento enquanto ativo organizacional, desde sua criação e aquisição, passando pela sua transferência e uso, até o processo de assimilação e geração de novo conhecimento, em um ciclo que se retroalimenta constantemente.

\subsection{Gestão de documentos}

A gestão de documentos, surgida no período da Segunda Guerra Mundial, entre as décadas de 1940 e 1950, sobretudo nos Estados Unidos e Canadá, impôs uma nova agenda teórica e prática para a disciplina arquivística. Para Jardim (1987),

Desde o desenvolvimento da arquivologia como disciplina, a partir da segunda metade do século XIX, talvez nada a tenha revolucionado tanto quanto concepção teórica e os desdobramentos práticos da gestão ou a administração de documentos [...] (JARDIM, 1987, p. 35).

Desde 1940, nos Estados Unidos e nos países anglo-saxônicos, é no âmbito administrativo e não arquivístico, que se inicia o desenvolvimento do conceito de gestão de documentos (INDOLFO, 2007). Tratava-se, inicialmente, de otimizar o funcionamento da administração, racionalizando a produção documental e estabelecendo prazos de guarda para os documentos (INDOLFO, 2007).

Portanto, a gestão de documentos surge a partir das necessidades impostas pelo grande aumento na produção de documentos ocorrida no período entre a Segunda Guerra Mundial (segunda metade dos anos de 1940), fruto do avanço dos métodos de produção e reprodução de documentos (LLANSÓ SANJUAN, 2006; SILVA et al., 2009; INDOLFO, 2007; JARDIM, 1987). A gestão de documentos teve como primeiro objetivo resolver o problema das massas documentais acumuladas (decorrentes do processo de acumulação desordenada dos documentos), com a criação dos chamados arquivos intermediários ou pré-arquivos (SILVA et al., 2009), e da intervenção e controle do ciclo de vida dos documentos (INDOLFO, 2007). Influenciada pelos métodos da administração moderna (INDOLFO, 2007), a gestão de documentos tem como finalidade "[...] controlar e racionalizar as atividades desde a produção e uso até a destinação final dos documentos." (INDOLFO, 2007, p. 
45) e, por objetivo, atender as demandas por economia, eficiência e eficácia (JARDIM, 2015).

Llánsó Sanjuan (2006) pontua que no âmbito do surgimento do conceito de gestão de documentos há uma forte incidência do fator econômico com a redução do volume documental - massa documental acumulada - e posteriormente, nas fases de produção, uso e destinação final, reduzindo ao mínimo o volume de documentos que se devem conservar por conta de seu valor histórico (LLANSÓ SANJUAN, 2006).

A partir da pesquisa conceitual em torno da gestão de documentos, realizada por Jardim (2015), nos instrumentos terminológicos do campo arquivístico, em língua inglesa, francesa, espanhola e portuguesa, destacam-se (Quadro 3) as percepções do autor em torno das ações, objetos e objetivos da gestão de documentos presentes nas definições analisadas.

Quadro 3 - Ações, objetos e objetivos da gestão de documentos.

\begin{tabular}{|l|l|l|l|}
\hline \multicolumn{1}{|c|}{ Língua } & \multicolumn{1}{|c|}{ Ações } & \multicolumn{1}{c|}{ Objetos } & \multicolumn{1}{c|}{ Objetivos } \\
\hline inglesa & $\begin{array}{l}\text { planejamento, controle e } \\
\text { direção }\end{array}$ & $\begin{array}{l}\text { produção, manutenção, uso } \\
\text { e destinação de documentos }\end{array}$ & $\begin{array}{l}\text { economia e a } \\
\text { eficiência }\end{array}$ \\
\hline francesa & controle & $\begin{array}{l}\text { produção, conservação, uso } \\
\text { e destinação de documentos }\end{array}$ & eficácia \\
\hline espanhola & $\begin{array}{l}\text { controle, o planejamento, } \\
\text { e a análise da produção, } \\
\text { tramitação, uso e } \\
\text { informação contida nos } \\
\text { documentos }\end{array}$ & $\begin{array}{l}\text { produção, uso, manutenção, } \\
\text { conservação, controle físico } \\
\text { e intelectual } \\
\text { de documentos íntegros, } \\
\text { autênticos e confiáveis }\end{array}$ & $\begin{array}{l}\text { eficiência e } \\
\text { estabelecimento de } \\
\text { normas }\end{array}$ \\
\hline portuguesa & controle & $\begin{array}{l}\text { produção, tramitação, } \\
\text { classificação, uso, avaliação } \\
\text { e arquivamento }\end{array}$ & $\begin{array}{l}\text { a eficácia, a } \\
\text { eficiência e a } \\
\text { racionalização }\end{array}$ \\
\hline
\end{tabular}

Fonte: Adaptado de Jardim (2015).

A gestão de documentos é instrumentalizada a partir de um conjunto de operações técnicas, que abrangem os arquivos correntes e intermediários (INDOLFO, 2007), dentre elas a classificação e a avaliação de documentos de arquivo. Para Indolfo (2007)

[...] a vinculação entre a classificação e a avaliação é primordial para garantir o controle dos fluxos informacionais, o acesso e a disponibilização da informação. [além disso] Só essas práticas permitem o compartilhamento das informações para a tomada de decisão segura e transparente, a preservação dos conjuntos documentais para a guarda permanente, e asseguram que a eliminação, daqueles documentos destituídos de valor [...] (INDOLFO, 2007, p. 45). 
A classificação assegura que os documentos sejam classificados a partir de planos ou códigos de classificação que reflitam as funções e as atividades da instituição produtora dos documentos, evidenciando as relações orgânicas entre os documentos, sob a forma hierárquica manifestada a partir do plano ou código de classificação. A utilização de uma codificação numérica para apontar as hierarquias das classes, subclasses, grupos e subgrupos, nos códigos de classificação, agilizar a ordenação e a localização física e lógica (INDOLFO, 2007).

Já em relação à avaliação dos documentos de arquivo, esta tem por objetivo reduzir ao máximo o volume de documentos produzidos por uma instituição, devido à impossibilidade de armazenar, preservar e dar acesso a tudo o que é produzido, mas mantendo o que foi destinado à guarda perene um conjunto de documentos "útil" e "valioso" (RHOADS, 1983, p. 1).

A gestão de documentos, a partir do estabelecimento e implementação de diretrizes e procedimentos relativos aos arquivos correntes e intermediários, permite "[...] tirar o máximo proveito da informação disponível e essencial a uma tomada de decisão esclarecida [...]" (ROUSSEAU; COUTURE, 1998, p. 118). Ainda, dentre as vantagens da aplicação das práticas da gestão de documentos, destacam-se a "[...] a aceleração da pesquisa de informação e o facto de obter de forma mais rápida a informação pertinente [...] [e] [...] a tomada de decisão de forma esclarecida graças à informação pertinente [...]" (COUTURE; ROUSSEAU, 1998, p. 119).

\section{Análise comparada}

A partir da revisão conceitual demonstrada na seção anterior, será apresentado nesta seção os resultados da análise comparativa entre os dois modelos de gestão, objetos de análise desta pesquisa. O Quadro 4 procura evidenciar as aproximações e distanciamentos da gestão do conhecimento e da gestão de documentos a partir de seguintes eixos: origens, objetos, objetivos e metodologia. 
Quadro 4 - Análise comparada da gestão do conhecimento e gestão de documentos

\begin{tabular}{|c|c|c|}
\hline \multirow{2}{*}{$\begin{array}{c}\text { Eixos de } \\
\text { comparação }\end{array}$} & \multicolumn{2}{|c|}{ Modelos de gestão } \\
\hline & Gestão do conhecimento & Gestão de documentos \\
\hline Origens & $\begin{array}{l}\text { - década de } 1980 \text { e } 1990 \\
\text { (TZORTZAKI; MIHIOTIS, 2014). } \\
\text { - busca por melhoria de negócios e } \\
\text { vantagem competitiva (OWEN, 1999; } \\
\text { TZORTZAKI; MIHIOTIS, 2014). }\end{array}$ & $\begin{array}{l}\text { • década de 1940; pós Segunda Guerra } \\
\text { Mundial (INDOLFO, 2007; JARDIM, } \\
\text { 1987; SILVA et al., 2009). } \\
\text { • aumento da produção documental e } \\
\text { acumulação desordenada de } \\
\text { documentos (INDOLFO, 2007; SILVA } \\
\text { et al., 2009). }\end{array}$ \\
\hline Objetos & $\begin{array}{l}\text { - conhecimento como conceito } \\
\text { (OWEN, 1999). } \\
\text { - conhecimento individual e coletivo } \\
\text { (OWEN, 1999), pessoas como objeto. }\end{array}$ & $\begin{array}{l}\text { - documento arquivístico (INDOLFO, } \\
\text { 2007). } \\
\text { • produção, utilização e destinação } \\
\text { final dos documentos (JARDIM, } \\
\text { 1987). }\end{array}$ \\
\hline Objetivos & $\begin{array}{l}\text { - desenvolvimento, inovação, criação } \\
\text { de valor agregado, melhoria de } \\
\text { processos e negócio (OWEN, 1999; } \\
\text { TZORTZAKI; MIHIOTIS, 2014; } \\
\text { WIIG, 1997). }\end{array}$ & $\begin{array}{l}\text { - controle, racionalização, eficiência, } \\
\text { eficácia e economia (INDOLFO, 2007; } \\
\text { JARDIM, 2015). } \\
\text { - reduzir o volume de documentos } \\
\text { (LLANSÓ SANJUAN, 2006; } \\
\text { RHOADS, 1983). }\end{array}$ \\
\hline Metodologia & $\begin{array}{l}\text { - procedimentos e sistemas para } \\
\text { produção, aquisição, organização, } \\
\text { transferência, uso dos ativos de } \\
\text { conhecimento (OWEN, 1999; WIIG, } \\
\text { 1997). } \\
\text { • conversão de conhecimento tácito } \\
\text { em conhecimento explícito } \\
\text { (NONAKA; KONNO, 1998; OWEN, } \\
\text { 1999). }\end{array}$ & $\begin{array}{l}\text { - intervenção e controle no ciclo de } \\
\text { vida dos documentos (desde a } \\
\text { produção e uso até a destinação final } \\
\text { dos documentos) (INDOLFO, 2007). } \\
\text { - conjunto de operações técnicas nos } \\
\text { arquivos correntes e intermediários } \\
\text { (INDOLFO, 2007). } \\
\text { - classificação e avaliação arquivística } \\
\text { (INDOLFO, 2007). }\end{array}$ \\
\hline
\end{tabular}

Fonte: Adaptado de Indolfo (2007), Jardim (1987, 2015), Llansó Sanjuan (2006), Nonaka e Konno (1998), Nonaka, Toyama e Konno (2000), Owen (1999), Rhoads (1983), Silva e outros (2009), Tzortzaki e Mihiotis (2014), e Wiig (1997).

É possível perceber que ambos os modelos de gestão possuem como origens necessidades gerenciais e econômicas. Enquanto a gestão de documentos surge para resolver o problema das massas documentais acumuladas e da produção desordenada de documentos, a gestão do conhecimento passa a existir objetivando a melhoria de negócios e inovação, na busca por vantagem competitiva.

A partir da necessidade de alcançar a vantagem competitiva, a gestão do conhecimento cresce tendo como objeto o conhecimento individual e coletivo. $\mathrm{O}$ conhecimento como conceito, centrado nas pessoas, é a base para o desenvolvimento de inovação nas organizações.

A gestão de documentos tem seus objetivos atrelados aos preceitos da administração moderna: a economia, a eficiência, a eficácia e o controle e 
racionalização da produção documental, a partir da intervenção no ciclo de vida dos documentos. A gestão de documentos centra-se no documento arquivístico como objeto.

A gestão do conhecimento possui como objetivo a inovação a partir de um elemento central: o conhecimento. Procura a melhoria de processos e negócios, vantagem competitiva e valor agregado para a organização.

Com relação às metodologias dos dois modelos de gestão, verifica-se que ambos estabelecem procedimentos que incidem na produção, organização e uso (ambos os modelos) e destinação (apenas na gestão de documentos). No caso da gestão de documentos, a partir do controle e intervenção no ciclo de vida dos documentos e no tocante a gestão do conhecimento, nos processos de organização, aquisição, organização, transferência e uso dos ativos de conhecimento.

O documento arquivístico é o objeto da gestão de documentos. Para a gestão do conhecimento, o documento arquivístico se apresenta como um ativo de conhecimento orgânico (conhecimento explicitado), contribuindo como fonte de informações para uso, assimilação e geração de novos conhecimentos (objeto da gestão do conhecimento), a partir da partilha, uso e reuso. Tendo como base este entendimento, pode-se compreender que é em torno do documento arquivístico $^{2}$ que ocorre a relação entre estes dois modelos de gestão, como pode ser observado por meio da Figura 2.

Figura 2 - Relações da informação, documento e documento arquivístico na gestão do conhecimento e na gestão de documentos

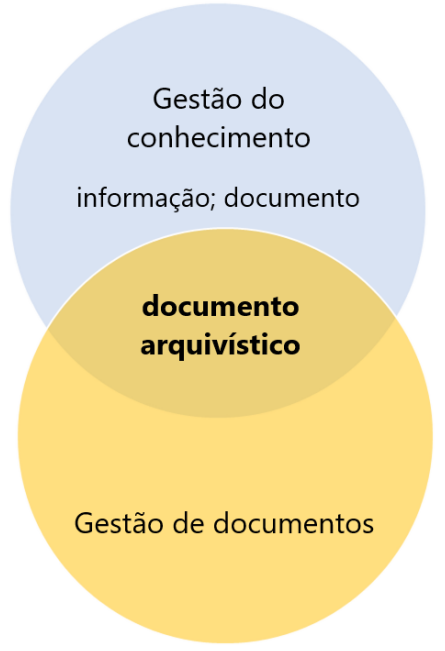

Fonte: Elaborado pelo autor. 
Percebe-se que os dois modelos de gestão estabelecem diversos pontos de conexão e de convergência, embora possuam propósitos diferenciados. A partir destas convergências, pontua-se abaixo (Gráfico 1) um esquema de cruzamentos metodológicos entre a gestão de documentos e a gestão do conhecimento, objetivando compreender a contribuição da primeira com a segunda.

Gráfico 1 - Contribuições da gestão de documentos (à esquerda) na gestão do conhecimento (à direita)

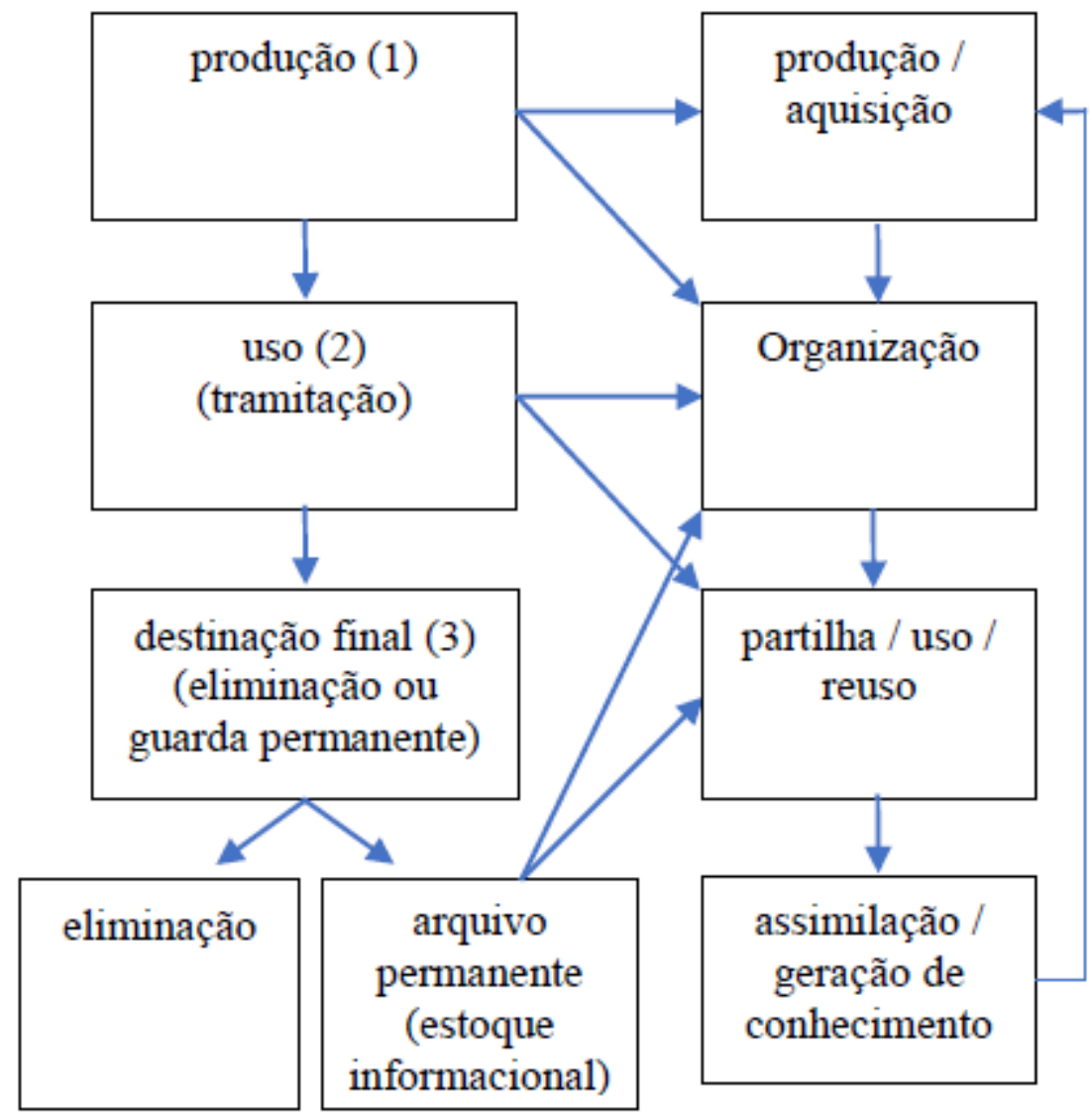

Fonte: Elaborado pelo autor.

No que concerne à gestão de documentos, a produção (1) abarca os seguintes elementos: “[...] desenho e gestão de formulários, preparação e gestão de correspondência, informes e diretrizes, fomento de sistemas de gestão da informação e aplicação das tecnologias modernas aos ditos processos." (RHOADS, 1983, p. 2, tradução nossa). O uso (2) compreende a criação de sistemas de arquivo e de recuperação da informação, gestão de registros, correio 
e telecomunicações, seleção e uso de equipamento reprográfico, análise de sistemas, produção e manutenção de programas de documentos vitais e uso de automação e reprografia nestes processos (RHOADS, 1983). A destinação (3) abrange a identificação e descrição das séries documentais, estabelecimento de programas de avaliação e destinação de documentos, eliminação ou recolhimento dos documentos de valor permanente ao arquivo (RHOADS, 1983).

A partir do Gráfico 1, aponta-se a contribuição da gestão de documentos na gestão do conhecimento nos seguintes aspectos: a produção, enquanto primeira fase da gestão de documentos, ocupa-se, como colocado por Rhoads (1983), dos processos e práticas que regem a produção documental, visando a sua racionalização (evitando a produção de documentos que não sejam essenciais), a elaboração de documentos de forma normalizada conforme padrões previamente estipulados e a classificação arquivística no ato da preparação dos documentos (de acordo com o código ou plano de classificação, estabelecendo seu contexto orgânico com os outros documentos). Com isso, relaciona-se a fase de produção, da gestão de documentos, com as fases de produção/criação e organização, da gestão do conhecimento, na medida em que as ações da primeira fase da gestão de documentos contribuem com a produção (racionalização e padrões de produção) e a organização (padrões de produção e estabelecimento da classificação arquivística e o contexto orgânico) da gestão do conhecimento.

A segunda fase da gestão de documentos, o uso, compreende os processos e práticas que envolvem a tramitação dos documentos, produzidos na fase anterior (produção), para cumprimento da função administrativa, sua organização e armazenamento. Abarcam esta fase os métodos de controle de tramitação dos documentos, as atividades de protocolo, a organização física e intelectual dos documentos e a elaboração de instrumentos de recuperação da informação nos arquivos correntes e intermediários. A fase de uso da gestão de documentos relaciona-se com as fases de organização e uso da gestão do conhecimento, pois estas envolvem também a organização, tendo em vista sua recuperação, e uso dos documentos (ativos de conhecimento orgânico). 
A terceira fase da gestão de documentos governa a avaliação e seleção dos documentos para destinação final, eliminação ou guarda permanente. Apesar de não estar relacionada com uma fase específica da gestão do conhecimento, esta fase da gestão de documentos é de vital importância para o seu processo: o estabelecimento dos prazos de guarda dos documentos e a sua destinação final, ou seja, a preservação permanente dos ativos de conhecimento orgânico (documentos arquivísticos) ou a eliminação dos documentos destituídos de valor. A constituição de um arquivo permanente de qualidade a serviço da gestão do conhecimento depende da implantação de um programa de gestão de documentos, mais especificamente de uma boa avaliação arquivística.

Após realizada a terceira e última fase da gestão de documentos, os documentos identificados como passíveis de valor secundário irão constituir o arquivo permanente da organização, estando à serviço da gestão do conhecimento nas fases de organização e uso.

No que tange ao uso, assimilação e geração de novo conhecimento, a partir da gestão do conhecimento, este pode ser novamente registrado transformado de conhecimento explícito para conhecimento explícito e/ou conhecimento tácito para conhecimento explícito (NONAKA; KONNO, 1998; NONAKA; TOYAMA; KONNO, 2000) e iniciar novamente os dois ciclos: da gestão de documentos e da gestão do conhecimento.

A partir desta análise exploratória da relação entre a gestão de documentos e da gestão do conhecimento, observa-se que estes dois modelos de gestão inequivocamente se interligam. Além disso, percebe-se o quanto a gestão de documentos pode contribuir com a gestão do conhecimento nas organizações.

\section{Considerações finais}

A gestão de documentos contribui para a gestão de conhecimento nas organizações, em uma de suas dimensões: os documentos arquivísticos produzidos e recebidos pela própria instituição no decorrer de suas atividades. Nessa perspectiva, a gestão de documentos tem uma dupla função:

a) o controle, a organização e o acesso à informação nos documentos de uso para o próprio produtor (idades corrente e intermediária), por 
meio da racionalização da produção documental e das práticas de controle, classificação e ordenação dos documentos;

b) a determinação da destinação final dos documentos (eliminação ou guarda permanente), por meio do processo de avaliação e seleção.

Destaca-se que enquanto a classificação organiza e dispõe os documentos arquivísticos hierarquicamente em classes e subclasses, conforme as funções e atividades para a qual foram produzidos, evidenciando suas relações orgânicas, permitindo sua recuperação; a avaliação identifica quais informações possuem valor secundário para guarda permanente, atuando decisivamente na construção do estoque informacional a ser preservado pela instituição, um de seus principais ativos em um processo de gestão do conhecimento.

Nesse sentido, essas atividades (classificação e avaliação) necessitam levar em consideração as necessidades informacionais da instituição, dentro de um processo de geração e uso do conhecimento, visando dispor à organização uma informação que seja relevante dentro de um processo de vantagem competitiva e tomada de decisões.

Tal como ficou patente na discussão dos resultados, conclui-se, de um modo geral, que a gestão de documentos e a gestão do conhecimento guardam relações de aproximações entre seus métodos e que a gestão de documentos pode contribuir para melhorar os processos de gestão do conhecimento, no que tange aos ativos de conhecimento orgânico, mais especificamente, os documentos arquivísticos.

Embora não tenha sido o enfoque deste trabalho, coloca-se como perspectiva futura uma análise entrecruzada entre a gestão de documentos, a gestão do conhecimento e a gestão da informação. A gestão da informação objetiva "[...] identificar e potencializar recursos informacionais de uma organização ou empresa e sua capacidade de informação, ensinando-a a aprender e adaptar-se a mudanças ambientais.” (TARAPANOFF, 2006, p. 22), a partir de um ciclo informacional de geração, seleção/aquisição, representação, armazenamento, recuperação, distribuição e uso, em um ciclo ininterrupto (PONJUÁN DANTE, 1998, p. 47). 
Esta análise tende a evidenciar como a gestão do conhecimento pode valer-se da contribuição dos dois modelos de gestão ligados a "[...] disciplinas científicas voltadas para os documentos e para as instituições de guarda e disseminação dos registros do conhecimento humano [...]" (ARAÚJO, 2015, p. 3): a gestão de documentos a partir da Arquivologia e a gestão da informação "Decorrente da biblioteconomia especializada e da ciência da informação [...]" (TARAPANOFF, 2006, p. 22), sendo a Ciência da Informação uma ciência, de natureza interdisciplinar, que possui como objeto a informação (LE COADIC, 2004).

\section{Agradecimentos}

Agradecimento para a valiosa contribuição da Professora Doutora Maria Cristina Vieira de Freitas, da Faculdade de Letras da Universidade de Coimbra, na concepção deste artigo.

\section{Referências}

ARAÚJO, Carlos Alberto Ávila. O pensamento funcionalista na Arquivologia, na Biblioteconomia e na Museologia. PontodeAcesso, Salvador, v. 9, n. 2, p. 329, 2015.

\section{ARQUIVO NACIONAL (Brasil). Dicionário brasileiro de terminologia} arquivística. Rio de Janeiro: Arquivo Nacional, 2005.

BELLOTTO, Heloísa Liberalli. Arquivos permanentes: tratamento documental. Rio de Janeiro: FGV, 2004.

BRASCHER, Marisa; CAFÉ, Lígia. Organização da Informação ou Organização do Conhecimento? In: ENCONTRO NACIONAL DE PESQUISA EM CIÊNCIA DA INFORMAÇÃO, 9., 2008, São Paulo. Anais [...]. São Paulo: ANCIB, 2008. p. 1-14.

CAMARGO, Ana Maria de Almeida; BELLOTTO, Heloísa Liberalli. Dicionário de terminologia arquivística. São Paulo: Associação dos Arquivistas Brasileiros, 1996.

COUTURE, Carol; ROUSSEAU, Jean Yves. Os fundamentos da disciplina arquivística. Lisboa: Dom Quixote, 1998. 




CRUZ MUNDET, José Ramón. Archivística: gestión de documentos y administración de archivos. Madrid: Alianza Editorial, 2012.

INDOLFO, Ana Celeste. Gestão de documentos: uma renovação epistemológica no universo da arquivologia. Arquivística.net, Rio de janeiro, v. 3, n. 2, p. 2860, dez. 2007.

JARDIM, José Maria. Caminhos e perspectivas da gestão de documentos em cenários de transformações. Acervo, Rio de Janeiro, v. 28, n. 2, p. 19-50, dez. 2015.

JARDIM, José Maria. O conceito e a prática de gestão de documentos. Acervo, Rio de Janeiro, v. 2, n. 2, p. 35-42, dez. 1987.

LE COADIC, Yves-François. A ciência da informação. Brasília: Briquet de Lemos, 2004.

LLANSÓ SANJUAN, Joaquim. Sistemas archivísticos y modelos de gestión de documentos en el ámbito internacional (Parte 1). Códice, Andaluzia, v. 2, n. 1, p. 53-88, 2006.

MOLEIRO MARTINS, José. Gestão do conhecimento: criação e transferência do conhecimento. Lisboa: Sílabo, 2010.

NONAKA, Ikujiro; KONNO, Noboru. The concept of "Ba": building a foundation for knowledge creation. California Management Review, Thousand Oaks, v. 40, n. 3, p. 40-54, 1998.

NONAKA, Ikujiro; TOYAMA, Ryoko; KONNO, Noboru. SECI, Ba and leadership: a Unified Model of Dynamic Knowledge Creation. Long Range Planning, [s.l.], v. 33, n. 1, p. 5-34, 2000.

OWEN, John Mackenzie. Knowledge management and the information professional. Information services \& use, [s.l.], v. 19, n. 1, p. 7-16, jan. 1999.

PINHEIRO, Lena Vania Ribeiro. Informação: esse obscuro objeto da ciência da informação. Morpheus, Rio de Janeiro, v. 3, n. 4, p. 1-11, 2004.

PONJUÁN DANTE, Gloria. Gestión de información en las organizaciones: principios, conceptos y aplicaciones. Santiago de Chile: CECAPI, 1998.

RHOADS, James Berton. La función de la gestión de documentos y archivos en los sistemas nacionales de información: un estudio del RAMP. Paris: UNESCO, 1983.

SHARIQ, Syed. Knowledge management: an emerging discipline. Journal of Knowledge Management, [s.l.], v. 1, n. 1, p. 75-82, set. 1997. 
SILVA, Armando Malheiro et al. Arquivística: teoria e prática de uma ciência da informação. Porto: Afrontamento, 2009.

TARAPANOFF, Kira. Informação, conhecimento e inteligência em corporações: relações e complementaridade. In: TARAPANOFF, Kira (org.). Inteligência, informação e conhecimento em corporações. Brasília: IBICT, 2006. p. 19-35.

TZORTZAKI, Alexia Mary; MIHIOTIS, Athanassios. A review of Knowledge Management Theory and future directions. Knowledge and Process

Management, [s.l.], v. 21, n. 1, p. 29-41, 2014.

VALENTIM, Marta Lígia Pomim. Gestão da informação e gestão do conhecimento em ambientes organizacionais: conceitos e compreensões.

Tendências da Pesquisa Brasileira em Ciência da Informação, Brasília, v. 1, n. 1, p. 1-16, 2008.

VALENTIM, Marta Lígia Pomim et al. O processo de inteligência competitiva em organizações. DataGramaZero, Rio de Janeiro, v. 4, n. 3, p. [s.l.], 2003.

WIIG, Karl Martin. Knowledge management: an introduction and perspective. Journal of Knowledge Management, [s.l.], v. 1, n. 1, p. 6-14, set. 1997.

\title{
The contribution of the records management in knowledge management in organizations: an exploratory approach
}

\begin{abstract}
This research seeks to verify how records management can contribute to knowledge management in organizations, exploring their approaches and their distances. It is an exploratory approach, whose methodological course starts from a literature review for a subsequent comparative analysis between the two management models that are the object of this work. The results point more towards an approximation than a distancing, evidencing the various contributions of records management in the process of knowledge management in organizations. It is concluded that knowledge management can benefit from a quality organic knowledge asset, in terms of records, when it results from the application of records management. That is, an organized, accessible organic asset, contextualized in its function/activity and organizational structure and with its identified values and established deadlines.
\end{abstract}

Keywords: Records Management; Knowledge Management; Knowledge Assets; Records. 
${ }^{1}$ A escolha do RCAAP deve-se ao repositório português integrar tanto os repositórios científicos de Portugal, quanto agregar o repositório brasileiro OASISbr, gerenciado pelo Instituto Brasileiro de Informação em Ciência e Tecnologia (IBICT), na busca. Assim, pôde-se efetuar uma cobertura maior e recuperar trabalhos científicos, em língua portuguesa, envolvendo Brasil e Portugal. O RCAAP e OASISbr agregam, em conjunto, 1034 recursos informacionais (218 do RCAAP e 816 do OASISbr), em um total aproximado de 2 milhões de documentos, com base nos dados disponibilizados pelo portal em abril de 2019.

${ }^{2}$ Como pode ser visualizado na Figura 2, o conhecimento explicitado (ativo de conhecimento orgânico) pode ser uma informação ou documento, sendo neste caso objeto da gestão da informação. Esta pesquisa centra-se no objeto da gestão de documentos, que é o documento arquivístico. O documento arquivístico é o ponto de interseção entre estes dois modelos de gestão. Se para a gestão de documentos ele é o seu objeto, para a gestão do conhecimento ele se constitui em um ativo. Nesse sentido, é a partir disso que a gestão de documentos contribui nas fases da gestão do conhecimento. 